The Bangladesh Veterinarian (2008) 25(1) : 1 - 8

\title{
Role of omentum in wound healing of goats
}

\author{
A. A. M. Bhuyan, M. M. Rahman*, M. A. Hashim, M. K. Islam ${ }^{1}$, M. N. Islam ${ }^{2}$ \\ and A. Islam \\ Departments of Surgery and Obstetrics, Faculty of Veterinary Science, Bangladesh \\ Agricultural University, Mymensingh-2202, Bangladesh
}

\begin{abstract}
The role of omentum with or without antibiotic administration was evaluated in the healing of external wounds in goats. Nine goats aged 8-10 months and weighing 7-8 kg was randomly allocated into 3 groups as A: treated with omentum, B: omentum plus antibiotic and C: control. Experimental wounds about $2.5 \mathrm{~cm}$ long and $0.5 \mathrm{~cm}$ deep was produced on each side of the midline at the lumber region in each goat. Omentum $2 \mathrm{~cm}$ long and $0.4 \mathrm{~cm}$ wide obtained from an abattoir were lodged between the wound edges and apposed with nylon thread by simple interrupted suture. Complete healing was obtained on 11, 13 and 19 days in groups B, A and C, respectively. Rectal temperature, heart and respiratory rates showed no significant $(\mathrm{p}>0.05)$ variation during the healing period. On histopathological studies, highest degree of inflammation was observed in group $C$ till day 15 , but on day 5 in groups $A$ and $B$. The rates of fibrosis of collagen fibre, epithelialization and neo-vascularization were most intensive in group $\mathrm{B}$ and then in group $\mathrm{A}$ and $\mathrm{C}$ till day 10. It is suggested that omentum along with antibiotic showed good healing in goats. (Bangl. vet. 2008. Vol. 25, No. 1, 1-8)
\end{abstract}

\section{Introduction}

Chronic wounds are a challenge for health care. A considerable number of surgical affections are found in goats and associated with defects that affect leather quality, performance or death. A basic principle of clinical management is the removal of sloughing necrotic tissue to prevent wound infection, which delays healing (Wollina et al., 2000). The healing of wounds may be delayed or absent due to improper development of angioblast and fibroblast (Ghosh, 2006). Over several decades, omental transposition has been applied in the treatment of wounds due to its angiogenic, immunologic and bulk resulting in accelerated healing (Goldsmith, 2004). The omentum is used for reconstruction of intra and extra-abdominal wounds (Avital et al., 2002). The omental flaps have been used for the reconstruction of complex defect of chest wall following debridement of infections of sternum and mediastinum (Acarturk et al., 2004). Its pedicle graft has been used successfully in the clinical management of chronic non-healing wounds of the axilla (Lascelles and White, 2001). Vascular endothelial growth factor (VEGF)-A of omentum stimulates angiogenesis because its binding to VEGF receptors promotes endothelial cell

\footnotetext{
1 Department of Physiology, Faculty of Veterinary Science, Bangladesh Agricultural University, Mymensingh, Bangladesh

2 Department of Anatomy and Histology, Faculty of Veterinary Science, Bangladesh Agricultural University, Mymensingh, Bangladesh

Correspondence :- E-mail : mizandsbau@hotmail.com
} 
migration and proliferation, which are required for the development of new blood vessels (Ferrara, 2002). VEGF-A increases vascular permeability that may contribute to angiogenesis. There has, however, been no study of the efficacy of omentum on the skin wound in goats. The present investigation was carried out to explore the feasibility of using the omentum for the treatment of external wound with or without antibiotic coverage.

\section{Materials and Methods}

Experimental animals

A total of nine goats (Capra hircus), three male and six female, aged 8-10 months, weighing $7-8 \mathrm{~kg}$ were used.

\section{Management of animals}

The experimental animals were purchased from the local market. The animals were kept on tethered grazing and supplied with $500 \mathrm{gm}$ bran and concentrate mixture in two meals and drinking water ad libitum. The goats were dewormed with albendazol (Almex®, Square Pharmaceuticals Ltd, Bangladesh) @ 7.5 mgkg-1.

\section{Experimental design}

The goats were randomly divided into three groups, A, B and C. In group A, only omentum flaps were used. The flaps of omentum were trimmed to $2 \mathrm{~cm}$ long by $0.4 \mathrm{~cm}$. The omentum was put into the depth of the wound and sutured. In group B, omental flaps were used in combination with antibiotic. Procaine penicillin with streptomycin sulphate $\left(\right.$ Streptopen $^{\circledR}$, Reneta Animal Health Ltd, New DOHS, Mohakhali, Dhaka) was injected daily for 5 days intramuscularly at $15 \mathrm{mgkg}^{-1}$. In group $\mathrm{C}$, neither omental flap nor antibiotic was administered, only normal saline $(0.9 \% \mathrm{NaCl})$ was used to six wounds produced in three animals. The wounds were sutured with nylon thread by the pattern of simple interrupted and the group was kept as control. Wounds were cleaned daily with distilled water with the help of sterile gauze. Animals were maintained carefully to avoid contamination or infection. Movement of animals was restricted to prevent granulation tissue formation.

\section{Source of omentum}

Goat's omentum was collected immediately after slaughtering from the local abattoir and kept in normal saline. Omentum was sliced as a flap of $2 \mathrm{~cm}$ by $0.4 \mathrm{~cm}$ with the help of scalpel and tissue forceps on sterile Petri dishes. The flap was used in the wound within one hour of collection.

\section{Antibiotics used}

Procaine penicillin with streptomycin sulphate (Streptopen ${ }^{\circledR}$, Renata Animal Health, New DOHS, Mohakhali, Dhaka, Bangladesh) was used to counter bacterial infection. 


\section{Preparation of the wound}

The operation sites were cleaned and painted with ethyl alcohol, and infiltrated with $2 \%$ lignocaine hydrochloride (Jasocaine ${ }^{\circledR}$, Jayson Pharmaceuticals Ltd., Dhaka, Bangladesh). On day 0, two incisions, each $2.5 \mathrm{~cm}$ long and $0.5 \mathrm{~cm}$ deep were made on either side of the midline of the lumber region.

\section{Gross observations}

The condition of wounds was monitored and the progress of healing recorded. The duration of wound healing, exudation, haemorrhage, oedema, inflammation, stitch abscess, rupture of stitch were recorded up to complete healing. A wound was assumed to be healed when cicatrisation and pigmentation were found. Evidence of pain was ascertained by palpation of the wound and its area.

\section{Biopsy and Histopathology}

The biopsies were collected from the wound areas of each experimental animal on day 3, 5, 7, 10 and 15 with standard surgical procedure. About $1.5 \times 1.5 \mathrm{~cm}$ of tissues was collected and the samples containing dermis and epidermis were kept in $10 \%$ buffered neutral formalin for 9 days. The tissues were trimmed and fixed for 24 hours in buffered formalin. Tissues were kept in running tap water overnight to wash out formalin and dehydrated in 50\%, 70\%, 80\% and 95\% alcohol and three changes of absolute alcohol for one hour each. The sections were cleaned in chloroform by two changes, one and half an hour for each. Tissues were embedded in paraffin, sectioned (5- $\mu \mathrm{m}$ thick), stained with Haematoxylin and Eosin, and examined under light microscope.

\section{Statistical analysis}

The data were statistically analyzed by Complete Randomized Design (CRD) one-factor test.

\section{Results and Discussion}

Exudation, pain and haemorrhage were observed in all three groups from day 0 (Table 1). The wound remained red from day 0 to day 5 in the group treated by omentum plus antibiotic (B), day 7 in the group treated by omentum alone (A) and day 10 in the control group (C). Severe reddening was found on day 3 in group A and B and day 5 in group C. Oedema at the wound site was observed in all three groups up to day 10. Maximum swelling was observed at day 3 in group A and B and day 5 in group $C$. This swelling gradually diminished, and disappeared on day 10 in groups A and B and on day 15 in group C. Pain persisted up to day 5 in group $A$ and $B$ and up to day 7 in group C. Highest degree of pain was observed on day 3 in all three groups. On day 10, a strong scar tissue was seen in group A and B and on day 15 in group C. Healthy scar formation was completed on day 15 in group A and B, but it was partially completed on day 15 in group C. No stitch abscess was found in group B. One stitch abscess was noticed in group A on day 10 and it persisted up 
to day 12. Two stitch abscesses were noticed in group C. Wounds in group A, B and C were healed completely on day 13,11 , and 19 , respectively.

Table 1. Gross changes in wounds

\begin{tabular}{|c|c|c|c|c|}
\hline Day & Change & Group A & Group B & Group C \\
\hline \multirow[t]{3}{*}{1} & Exudation & + & + & + \\
\hline & Pain & + & + & + \\
\hline & Haemorrhage & + & + & + \\
\hline \multirow[t]{3}{*}{3} & Reddening & ++ & ++ & +++ \\
\hline & Swelling & +++ & +++ & ++ \\
\hline & Pain & ++ & ++ & +++ \\
\hline \multirow[t]{3}{*}{5} & Reddening & ++ & ++ & +++ \\
\hline & Swelling & ++ & ++ & +++ \\
\hline & Pain & + & + & ++ \\
\hline \multirow[t]{3}{*}{7} & Reddening & + & - & ++ \\
\hline & Swelling & + & + & ++ \\
\hline & Pain & - & - & + \\
\hline \multirow[t]{5}{*}{10} & Reddening & - & - & + \\
\hline & Swelling & + & + & ++ \\
\hline & Pain & - & - & - \\
\hline & Scar formation & ++ & ++ & - \\
\hline & Stitch abscess & + & - & + \\
\hline \multirow[t]{3}{*}{15} & Swelling & - & - & - \\
\hline & Scar formation & Complete & Complete & ++ \\
\hline & Stitch abscess & - & - & +++ \\
\hline 20 & Stitch abscess & - & - & - \\
\hline
\end{tabular}

$+=$ Mild,$++=$ Moderate,$+++=$ Massive,$-=$ Absent

The highest rectal temperature, heart and respiratory rates in group A were 39.2 $\pm 0.5^{\circ} \mathrm{C}, 63.7 \pm 1.2 / \mathrm{min}$ and $43.3 \pm 1.2 / \mathrm{min}$, respectively and the lowest rectal temperature, heart and respiratory rates were $38.9 \pm 0.1^{\circ} \mathrm{C}, 61.0 \pm 1.0 \mathrm{~min}$ and $41.0 \pm$ $1.0 / \mathrm{min}$, respectively. The changes are not statistically significant $(\mathrm{p}>0.05)$. The highest rectal temperature, heart and respiratory rates in group $\mathrm{B}$ were $39.1 \pm 0.1^{\circ} \mathrm{C}$, $64.7 \pm 1.0 / \mathrm{min}$ and $28.7 \pm 1.2 / \mathrm{min}$, respectively, and the lowest rectal temperature, heart and respiratory rates were $39.0 \pm 0.2^{\circ} \mathrm{C}, 61.3 \pm 1.15 \mathrm{~min}$ and $27.0 \pm 1.0 / \mathrm{min}$, respectively. The changes are not statistically significant $(p>0.05)$. The highest rectal temperature, heart and respiratory rates in group $\mathrm{C}$ were $39.1 \pm 0.1^{\circ} \mathrm{C}, 62.7 \pm 1.2 / \mathrm{min}$ and $27.3 \pm 1.2 / \mathrm{min}$, respectively, and the lowest rectal temperature, heart and respiratory rate were $38.9 \pm 0.2^{\circ} \mathrm{C}, 61.0 \pm 1.1 \mathrm{~min}$ and $26.3 \pm 0.6 / \mathrm{min}$, respectively. The changes are not statistically significant $(\mathrm{p}>0.05)$. 
Histological assessment of biopsies taken from various treatment groups was focused on the regeneration of epidermis, proliferation of fibrous connective tissue, development of new blood vessels and degree of inflammation. The highest degree of inflammation was observed in the control group (Fig. 3), followed by the group A (Fig. 1). Mild inflammation was observed in group B (Fig. 2) on day 5. The lowest degree of inflammation was observed in all groups after day 15. In group B, the predominant tissue response was the development of new blood vessels and fibrous connective tissue proliferation. While in other groups mild to moderate fibrous connective tissue proliferation and neo-vascularization was observed. There was marked thickening of the gap between the wound edges in the control group due to marked deposition of inflammatory exudates.

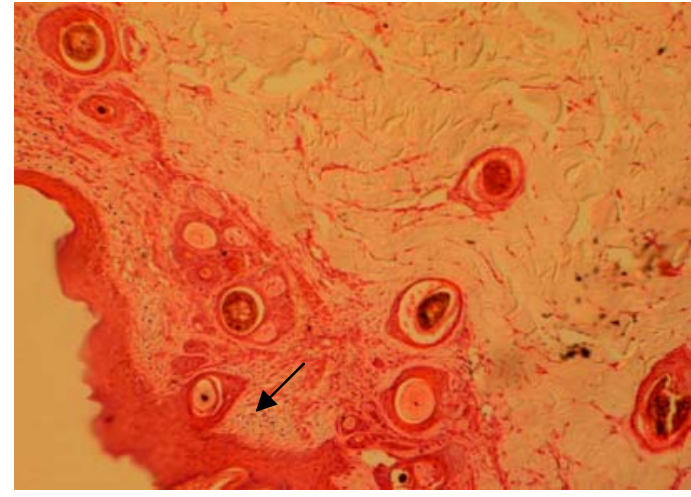

Fig. 1. Biopsy at day 5 from goat treated with omentum. Arrow indicates moderate infiltration of reactive cells specially lymphocytes and macrophages (400X)

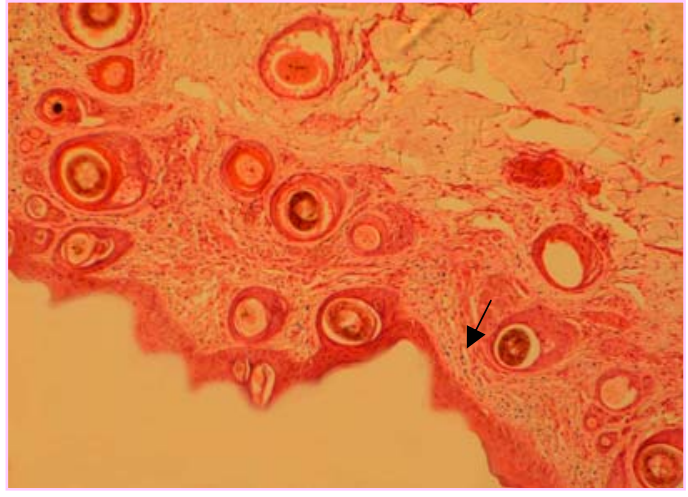

Fig. 2. Biopsy at day 5 from goat treated with omentum and antibiotic. Arrow indicates mild infiltration of reactive cells specially lymphocytes and macrophages (400X)

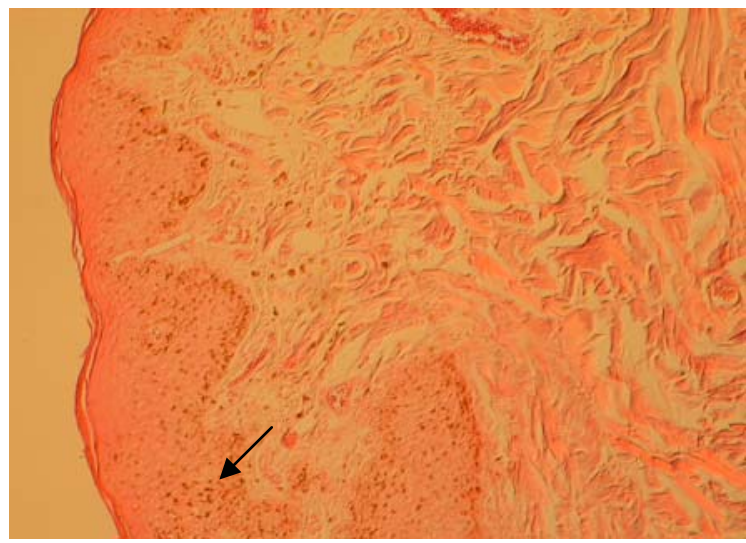

Fig. 3. Biopsy at day 5 from control goat. Arrow indicates massive infiltration of reactive cells specially lymphocytes and macrophages (400X) 
The epithelial lining of the epidermis started regenerating from the edge of the wound on day 7 in the groups treated with omentum, but not in control group. The healed tissue showed histological restoration of the collagen tissue of the dermis and the response appeared to be massive in the group treated with omentum and antibiotic, moderate in the group treated with omentum alone and mild in the control group.

On day 7, the thickening of fibrous tissue was reduced in the healed tissue in both the treated groups. Variable-sized empty spaces in the fibrous connective tissue were seen in the control group and that treated with omentum alone. Keratinized layer was developed in all groups on day 15. Keratinized layer was thickest in the group treated with omentum plus antibiotic and thinnest in the control group.

Autoimmune reaction was negligible in groups A and B. Autoimmune reaction was defensible by gross observation such as itching sensation, laceration as well as oozing from the wound. Due to experimental limitation autoimmune reaction could not be justified by biochemical examination.

No definite pattern of changes in heart and respiratory rates were recorded in any group. Similar results have been reported earlier (Yeasmin, 1992). Rise of rectal temperature was recorded during postoperative phase. This may be due to surgical trauma and thereafter due to acute suppurative inflammation. These parameters, however, returned to almost normal after healing, which agrees with the findings of Saini et al. (1992). In the present study, exudation, reddening, swelling, pain, scab formation, granulation and scar formation were found in wound healing. The redness may be contributed from increased blood circulation and extravasation of blood components, and the swelling may result from exudation from blood vessels into the surrounding tissue (O'Connor, 1980). It gradually diminished, and disappeared on day 10 in groups A and B and by day 15 in the control group. One goat in the control group developed a hard subcutaneous mass, which could be an abscess (Mattra, 2004).

Gray (2005) used omentum in the treatment of wounds and found favourable results similar to those in this study. In addition, defects of chest wall have been treated successfully by omental flap due to rapid growing of blood vessels, epithelial cells and fibroblast (Acarturk et al., 2004).

There was more inflammation in the regenerating tissue in control group at day 3. However, the highest degree of fibrous connective tissue proliferation and neovascularization was observed in the group treated with omentum plus antibiotic followed by the group treated with omentum alone. This pattern of cellular proliferation was observed by Domene et al. (1998). Leukocytic infiltration was more pronounced in group B at day 3. Group A showed moderate leukocytic infiltration till day 5. This infiltration decreased from day 7 and decreased further on day 15. But the infiltration in control group was almost constant till day 15. At day 3, excessive infiltration of lymphocytes and macrophages and subsequent rapid healing were evident in groups $\mathrm{A}$ and $\mathrm{B}$. This could be due to removal of tissue debris by 
macrophages derived from omentum. The milky spots of omentum act as a source of macrophages and lymphocytes (Litbarg et al., 2007). Omentum reduces inflammatory complications. Immunological and bacteriological examination showed that pediculated omental flap is a source of lymphocytes and decreases $2.5 \mathrm{~cm}$ long and $0.5 \mathrm{~cm}$ deep bacterial quantity and activity (Levashev et al., 1999).

There was more fibroblast proliferation in group B, less in group A and least in the control in early phase of healing. But later on all groups exhibited similar fibroplasia. The intense fibroplasia in group B in the early phase might be due to the marked infiltration of macrophages and neutrophils. The area cleaned by macrophages and neutrophils that was later invaded by fibroblasts and angioblasts. Besides this, omentum acts as sources of mast cells, which possess profibrotic factor, which stimulates the fibroblastic process. From the observations on day 10 and day 15, it was evident that the process of fibroplasia in the treatment group had reached a plateau, heralding the initiation of maturation phase. Similar results were published by Cothier-Savey et al. (2001).

Neo-vascularization was more intense in the treated group B than in group A and control group $\mathrm{C}$ till day 10. This finding is close to the statements of Zhang et al. (1997). Vascular endothelial growth factor (VEGF)-A of omentum stimulates angiogenesis because its binding to VEGF receptors promotes endothelial cell migration and proliferation, which are required for the development of new blood vessels. In addition, VEGF-A increases vascular permeability, which may contribute to angiogenesis (Ferrara, 2002). Intense neo-vascularization and inflammatory responses in early stage of healing stimulates fibroblasts to synthesise collagen. Treated groups exhibited decreased vascularization on day 15 . The regression in vascularity marked the beginning of maturation phase. Epithelialization was conspicuous and started earlier in the treated groups than in control group.

Healing time varied from 11 to 15 days. Healing was faster in the group treated by omentum plus antibiotic, followed by omentum alone and was very slow in the control group. This confirms earlier findings (Avital et al., 2002; Domene et al., 1998).

In conclusion, omentum showed splendid results in the healing of external wounds in goats but the best result were achieved when omentum and antibiotic were applied together. Surgical wounds did not cause significant variation in clinical parameters in goats.

\section{References}

Acarturk TO, Swartz WM, Luketich J, Quinlin RF, Edington H 2004: Laparoscopically harvested omental flap for chest wall and intrathoracic reconstruction. Annals of Plastic Surgery 53 210-216.

Avital S, Rosin D, Brasesco O, Saber AA, Gupta A, Boyd B, Rosenthal RJ 2002: Laparoscopic mobilization of an omental flap for reconstruction of an infected sternotomy wound. Annals of Plastic Surgery 49 307-311. 
Cothier-Savey I, Tamtawi, B, Dohnt, F, Raulo Y, Baruch J 2001: Immediate breast reconstruction using a laparoscopically harvested omental flap. Plastic and Reconstructive Surgery 107 1156-1163.

Domene CE, Volpe P, Onari P, Szachnowicz S, Birbojm I, Barreira LF, Reiff AM, Pinotti HW 1998: Omental flap obtained by laparoscopic surgery for reconstruction of the chest wall. Surgical Laparoscopy and Endoscopy 8 215-218.

Ferrara N 2002: Role of vascular endothelial growth factor in physiologic and pathologic angiogenesis: therapeutic implications. Seminars in Oncology 29 10-14.

Ghosh SA 2006: Comparison of the effects of antibiotics and plant extracts for the treatment of wound in goats. MS Thesis, Department of Surgery and Obstetrics, Bangladesh Agricultural University, Mymensingh, Bangladesh.

Goldsmith HS 2004: The evolution of omentum transposition: From lymphedema to spinal cord, stroke and Alzheimer's disease. Neurological Research 26586 -593.

Gray MJ 2005: Chronic axillary wound repair in a cat with omentalisation and omocervical skin flap. Journal of Small Animal Practice $\mathbf{4 6}$ 499-503.

Lascelles BDX, White RAS 2001: Combined omental pedicle grafts and thoracodorsal axial pattern flaps for the reconstruction of chronic, nonhealing axillary wounds in cats. Veterinary Surgery 30 380-385.

Levashev YN, Akopov AL, Mosin IV 1999: The possibilities of greater omentum usage in thoracic surgery. European Journal of Cardiothoracic Surgery 15 465-468.

Litbarg NO, Gudehithlu KP, Sethupathi P, Arruda JA, Dunea G, Singh AK 2007: Activated omentum becomes rich in factors that promote healing and tissue regeneration. Cell and Tissue Research 328 487-497.

Mattra C 2004: Effects of penicillin on surgical wound healing in goats. MS Thesis, Department of Surgery and Obstetrics, Bangladesh Agricultural University, Mymensingh, Bangladesh.

O'Connor JJ 1980: Dollar's Veterinary Surgery. $4^{\text {th }}$ edn. CBS Publications and Distribution. pp. 20-47.

Saini N S, Sharma SN, Oberoi MS 1992: Evaluation of local and parenteral use of antibiotics during laparotomy in bovines. Indian Veterinary Journal 69 150-154.

Wollina U, Karte K, Herold C, Looks A 2000: Biosurgery in wound healing - the renaissance of maggot therapy. Journal of the European Academy of Dermatology and Venereology 14 285-289.

Yeasmin F 1992: Wound healing in Black Bengal Goats. MSc Thesis. Department of Surgery and Obstetrics, Bangladesh Agricultural University, Mymensingh, Bangladesh.

Zhang QX, Magovern CJ, Mack CA, Budenbender KT, Ko W, Rosengart TK 1997: Vascular endothelial growth factor is the major angiogenic factor in omentum: Mechanism of the omentum-mediated angiogenesis. Journal Surgical Research 67 147-154. 